\title{
Vocabulary Acquisition: What does It Mean to Know a Word?
}

\author{
Xin Zhang ${ }^{1 *}$ \\ ${ }^{1}$ English Language Center, Shantou University, Guangdong, China \\ *Xin Zhang, E-mail: zhangxin@stu.edu.cn
}

\begin{abstract}
This paper demonstrates vocabulary acquisition from psycholinguistics perspective, and tries to explain the questions through exploring the nature and the organization of the mental lexicon. It finally leads to pedagogical implication and provides suggestions for vocabulary teaching. Effective vocabulary instructions should contains the following characteristics: multiple exposures to instructed words, the establishment of ties between instructed words and students' own experience and prior knowledge.
\end{abstract}

Keywords

vocabulary, mental lexicon, lexical item

\section{Introduction}

It is probably that a large number of teachers and students will agree that learning vocabulary is an essential step to master a second language. As Eunmee (2008) claims, the most basic components of language use and development are words and phrases. Therefore, vocabulary has been widely accepted as the most important factor in the acquisition of another language. In spite of increasingly researches have devoted into the vocabulary learning and teaching, it is still not clear which is the most effective way to enhance the vocabulary learning. In addition, it is always confusing whether to comprehend a word or not, especially for the second language learners. And what does it mean to learn a new word? Certain conclusions have come to by reflecting on the nature and organization of mental lexicon. Many psychologists (Levelt, 1989; Schreuder \& Flores d'Arcais, 1989; Albrechtsen, Haastrup, \& Henriksen, 2008; Aitchison, 2003) indicate that people store representations of words in a mental dictionary and call this mental dictionary the lexicon. It is hypothesized to contain all the information that we know about a word, including its sounds (phonology), meaning (semantics), written appearance (orthography) and the syntactic roles it can adopt. When people know what the word is, people then have access to all the information about it, such as what it means and how to spell it.

In this article, it is hypothesized that every language user has a human word-store or a mental lexicon at first. Then, it is assumed that the mental lexicon includes a large sum of lexical entries, one for each lexical item. Lexical entry refers to the word in our mental lexicon. Third, it described the nature of the mental lexicon by considering what a lexical entry includes. If there is a satisfactory working definition of a lexical entry, it would be easier to get the answer for the question what it means to know a word 
and what it means to learn a new word.

\section{The Nature of the Mental Lexicon}

Schreuder and Flores d'Arcais (1989) describe the mental lexicon to stand for the store of all our knowledge related to words. In other words, the mental lexicon could be regarded as internalized knowledge of the properties of words.

When a lexical item is retrieved from the mental lexicon (in the productive mode), this is done on the basis of its meaning, but in addition to the meaning, it contains syntactic, morphological, and phonological information (Levelt, 1989, p. 6).

Levelt (1989) believes that each item in the mental lexicon is a listing of four kinds of features. These are meaning, syntactic properties, morphological specification of the item, and its phonology form. Besides that, systematic relations are existed in its meaning, syntactic properties, morphological specification and phonology form. In that case, there exists two kinds of internal organization in the mental lexicon: one according to the meaning of items and the other one on the basis of their form properties.

According what has been discussed above, the word in the mental lexicon contains two main components: 1) form which includes phonological and morphological information, and 2) meaning which contains semantic and syntactic information.

\subsection{Form}

Form includes phonological information, orthographic information and morphological information. To recognize a word, we need to know both phonological and orthographic form. However, given the fact that a speaker may have any one of a number of regional accents or that a written text may appear in any one of a number of different typefaces, there is existing variations of phonological and orthographic representations (Field, 2003, p. 12). Field (2003) regards the identification of a word as the result of a simple matching process. In other words, when encountering with the words in the speech, it is required to match it to the phonological form of the word; when encountering with the words in reading process, it is required to match it with orthographic form of the word. Furthermore, the two are closely connected to the same unit of meaning. Besides the situation that different form sharing the same unit of meaning, there is still another kind of situation related to the homonymy. The same phonological form may have associated with different meanings. Take "way" for an example, it may means a method, style or manner of doing something, or it may means a route or road that you are taken in order to reach a place.

Before considering precisely what it means to know a word, the question what constitute a lexical entry should be consider at first. It has been heated debated that all derived forms of a word should be regarded as an entry or as separate entries. According to Levelt (1989), the various inflections of a verb (e.g., eat, eats, ate, eaten, eating) are items belonging to the same lexical entry. The diacritic features for person, number, tense, mood, and aspect will take care of selecting the right item inflections (Levelt, 
1989). However, it is not the case for derivations; happy, unhappy, happiness, unhappiness, happily, etc. are different lexical entries (Field, 2003).

As what has been discussed above, an entry includes the base form of the word and its entire range of inflections. In the mental lexicon, therefore, a lexical entry, includes the base form of word and its inflections. If we knew a word, we need to know the base form and all the inflections. Take "take" for an instance, we would need to know "took", "takes", "taken", "taking". Besides the inflections, it is still needs to know the derivations. Take "act" for an example, it is still need to know "action", "activity", "actor" and so on. All in all, both inflections and derivational morphology of a word should be associated with the base form of the word and stored in the mental lexicon.

\subsection{Meaning}

As Schonefeld (2001) indicates, only a lexical entry's meaning and syntax are relevant. In order to have a better understanding of each lexical entry, it should be investigated from both semantic knowledge and syntactic knowledge.

Semantics offers a principled theory of the relationships between words. And it assumes three main kinds of association: semantic field, sense relations, and collocates. Semantic fields refer to the words which are grouped according to the topic area. For example: curriculum, entertainment facilities, etc. Linguists have identified several important sense relations which are linking words through similarities and difference of the meaning. Carroll (2004) defines those two words or expressions mean the same thing as synonymy, for instance, "fear" and "pan", "stupid" and "silly". Antonymy refers to opposition of meaning, for example: "old" and "young", "long" and "short". Hyponymy refers to the words that are member of the same category; that is , dog is a hyponym of animal, animal is a superordinate of dog, and within the category ANIMAL, dog and cat are co-hyponyms (Field, 2003, p. 60). When the syntactic conditions had been fulfilled, certain items in the lexicon will be activated during grammatical encoding (Field, 2003). It means that, therefore, it requires knowing its syntactic category, assignment of grammatical functions, and a set of diacritic feature variables, or parameters when knowing a word.

All in all, the most basic information needed to have in a lexical entry including form and the meaning of the word. To be more precise, a lexical entry includes phonological, orthographic, and morphological form. Besides this, a lexical entry also contains semantic and syntactic information. Thornbury and Harmer (2002) emphasized that knowing a word is need to know the sum total of all these information - semantic, syntactic, phonological, orthographic, morphological, cognitive, cultural and autobiographical. Therefore, when you know a word's form, meaning, semantic and syntactic information, you know the word. 


\section{The Organization of the Mental Lexicon}

Thornbury and Harmer (2002) argue that the way that the words are stored in the mental lexicon like a kind of network or web instead of a dictionary. The mental lexicon seems to store words in a highly organized and interconnected way rather than store words randomly. When it comes to the organization of the mental lexicon, people always compare the organization of the book dictionary with that of the mental lexicon. There is existing similarities between the two. However, the organization of the mental lexicon is probably to be much complex than that of book dictionary.

With regard to organization, book dictionaries list words in alphabetical order. However, human mental lexicon cannot be organized solely in alphabetical order (Thornbury \& Harmer, 2002). Evans and Green (2006) hold the points that mental lexicons is encyclopedic nature rather dictionary nature. Aitchison (2003) believes the mental lexicon is like a network, which is envisaged as an intricate, multi-layered structure or word web with numerous levels of interconnections between lexical items. Words are multi-dimensionally linked to each other through both form and meaning in the mental lexicon. The content of the mental lexicon is not fixed and updated all the time. It will add some new information or some new words in utterances. Furthermore, the mental lexicon is even produce new words or new meanings in speeches. The network metaphor has gained widely acceptance, and enormous psychological experiments have contributed to our understanding the organization of the mental lexicon. Word association experiments, Slips of the Tongue and Tip of the Tongue analysis has provide data to how the mental lexicon organized.

The results of word association experiments suggest that meaning associations in the lexicon are stronger than those based on similarity of pronunciation or spelling. The research of Slip of the Tongue, which implemented in 2003 by Field, it comes to the conclusion that the mental lexicon is organized on the basis of meaning. Thornbury and Harmer (2002) suggest that the mental lexicon is a semantic (meaning-based) organization, but the one has a form-based (or what is called morphological) back-up. According to Ding fang (2009), encyclopedic knowledge is not only playing an essential role in the meaning representation, but also offering explanations for meaning constructions that are larger than words.

All in all, what has been discussed above suggests the mental lexicon is based not only on the meaning but also on the form. The mental lexicon, therefore, as an overlapping system in which words are stored as "double entries" - one entry containing information about meaning and the other about form (Thornbury \& Harmer, 2002). The entries connected with each other from both meaning and form. When one word is a derivation of the other, they linked with each other in the mental lexicon. When one word has the similar meaning with the other word, they linked with each other in the mental lexicon. When one word has the similar pronunciation with the other words, they linked with each other. When one word has the similar spelling with the other word, they linked with each other in the mental lexicon. When one word and other words are in the same semantic grouping, they linked with each other in the mental lexicon. 
It means that the words are multidimensionally linked to each other through both form and meaning in the mental lexicon. In other words, it linked with each other like a web or network. The number of linking is enormous. Finding a word is like following a path or several paths through the network or the web.

Aitchison (2003) believes two central processes in lexical acquisition: mapping and network building. Mapping is the cognitive process of creating links between our conceptual knowledge (the semantic base) and the lexical form of the lexical entry (Albrechtsen, Haastrup, \& Henriksen, 2008). Simultaneously with the creation of links of between the word form and its meaning in the mapping process, it is assumed that a process of network building take place. As far as learning a new word is concerned, it is not only connected with its specific form-meaning but also connected with the network of the word in the mind through both form and meaning.

\section{The Pedagogical Implication}

Ellis (1994) has proved that there are specialized modules, the input and output lexicons, which require the word forms and regularities of the surface form of language by implicit learning process. In other words, it means that the form of the mental lexicon seems to be learnt implicit. And the learning of the form of the mental lexicon is related to the frequency, and regularity of the mental lexicon. According to the Ellis (1994), the meaning of the mental lexicon is likely to be learnt by explicit learning. Furthermore, it is heavily affected by depth of processing and elaborative integration with semantic and conceptual knowledge. In other words, it means that the learning of the meaning of the mental lexicon is explicit and relies on the meaning elaboration. All in all, form and meaning likely to be learnt by different ways. The form is learnt implicitly. In contrast, the meaning is learnt explicitly.

When it comes to the pedagogical implications, the pedagogical implications of meaning and those of form are different. Form-learning is heavily affected by its frequency. Albrechtsen, Haastrup and Henriksen (2008) suggest that the language learner could via repeated language exposure to constantly establish internal links between the lexical items in the mental lexicon. The word, therefore, was required to be repeated and increase its exposure, which would enhance the memory. At the same time, form-learning is related to its recency. Therefore, the word needed to be reviewed which would make the word more impressed. Furthermore, form-learning is connected with its regularity. So, words need to be learned and reviewed regularly. It would be an effective way to enhance memorization. According to the Nagy and Herman (1987), Vocabulary knowledge — knowledge about word meanings - is both subset of, and highly correlated with, general knowledge. It means that the specific word is highly related with other general words they have already known. Therefore, the learner should be encouraged to build systematic links with words they already know. The more links are established, the more likely that the word is going to be retained. When it comes to teaching, the instructions must aim at establishing rich ties between new words and prior knowledge and must present new words and concepts in the context of larger domains of knowledge (Nagy \& Herman, 1987, p. 32). Explicit, deep, 
elaborative processing concerning semantic and conceptual representations prevents the meaning of the word fading from our memory (Ellis, 1994, p. 28). In a sum, it would be much more effective for the vocabulary teaching, if the vocabulary instruction could contain the following characteristics: multiple exposures to instructed words, the establishment of ties between instructed words and students' own experience and prior knowledge.

\section{Conclusion}

In conclusion, an entry in the mental lexicon includes its form and meaning. To be more explicit, the form part of a lexical entry contains phonological, orthographic, and morphological form. The meaning part of a lexical entry contains semantic and syntactic information. It means that, therefore, knowing a word needed to know its form and meaning which includes phonological form, orthographic form, morphological form, semantic knowledge and syntactic knowledge. Take consideration of the organization of the mental lexicon, the words are multidimensionally linked to each other through both form and meaning in the mental lexicon. As far learning a new word concerned, it is not only connected with its specific form-meaning but also connected with the network of the word in the mind through dimensional ways. According to conclusion drawing from Ellis (1994), the form of the word is learnt implicitly while the meaning of the word is learnt explicitly. It leads to the different pedagogical implications on the form and the meaning of the word. Due to the fact that form-learning is highly influenced by its frequency of exposure, it would be more effective to use multiple exposures on instructed words. Because the words are connected with each other in the network of the mental lexicon, it is better to establish ties between instructed words and students' prior knowledge and own experience in the vocabulary teaching.

\section{References}

Aitchison, J. (2003). Words in the mind: An introduction to the mental lexicon. Oxford: Blackwell.

Albrechtsen, D., Haastrup, K., \& Henriksen, B. (2008). Vocabulary and Writing in a First and Second Language: Process and Development. New York: Palgrave Macmillan.

Carroll, D. W. (2004). Psychology of Language (4th ed.). Pacific Grove: Brooks/Cole Publishing Company.

Ding, F. S. (2009). Cognitive Approaches to Lexical Semantics. Language and Linguistics Compass, 3, 314-337. http://dx.doi.org/10.1111/j.1749-818X.2008.00120.x

Ellis, N. (Ed.). (1994). Vocabulary Acquisition: The implicit ins and outs of explicit cognitive mediation. In Implicit and Explicit Learning of Languages. London: Academic Press.

Eunmee, K. (2008). English vocabulary acquisition strategies. Retrieved from http://www.vdm-verlag.de

Evans, V., \& Green, M. (2006). Cognitive linguistics: An introduction. Edinburgh: Edinburgh University Press. 
Field, J. (2003). Psycholinguistics (A resource book for students). London: Routledge.

Levelt, W. J. M. (1989). Speaking: From intention to articulation. Cambridge, Mass.etc.: MIT.

Nagy, W. E., \& Herman, P. A. (1987). Breadth and depth of vocabulary knowledge: Implications for acquisition and instruction. In McKeown, \& Curtis (Eds.), The Nature of Vocabulary Acquisition (pp. 19-35). London: Lawrence Erlbaum.

Read, J. (2000). Accessing Vocabulary. Cambridge: CUP.

Schonefeld, D. (2001). Where Lexicon and Syntax meet. New York: Mouton de Gruyter.

Schreuder, R., \& Giovanni, Flores d'Arcais. (1989). Psycholinguistic issuse in the lexical representation of meaning. In W. Marslen-Wilson (Ed.), Lexical Representation and Process (pp. 409-435). Cambridge, Mass.etc.: MIT.

Thornbury, S., \& Harmer, J. (2002). How to teach vocabulary. Longman. 